\title{
Concepts of multifaceted social support in operational work in the lives of South African Police Service members
}

\author{
Author: \\ Masefako A. Gumani ${ }^{1}$ \\ Affiliation: \\ ${ }^{1}$ Department of Psychology, \\ University of South Africa, \\ South Africa \\ Correspondence to: \\ Masefako Gumani \\ Email: \\ gumanma@unisa.ac.za \\ Postal address: \\ PO Box 392, Pretoria 0003, \\ South Africa \\ Dates: \\ Received: 15 Mar. 2014 \\ Accepted: 15 Oct. 2014 \\ Published: 10 Dec. 2014 \\ How to cite this article: \\ Gumani, M.A. (2014). \\ Concepts of multifaceted \\ social support in operational \\ work in the lives of South \\ African Police Service \\ members. SA Journal of \\ Industrial Psychology/SA \\ Tydskrif vir Bedryfsielkunde, \\ 40(2), Art. \#1209, 11 pages. \\ http://dx.doi.org/10.4102/ \\ sajip.v40i2.1209

\section{Copyright:} \\ C 2014. The Authors. \\ Licensee: AOSIS \\ OpenJournals. This work is \\ licensed under the Creative \\ Commons Attribution \\ License.
}

\section{Read online:}

Scan this QR code with your smart phone or mobile device to read online.
Orientation: The extensive role that social support plays in the lives of South African Police Service (SAPS) members outside of the expected work networks of professionals and colleagues should be further studied to reflect on the benefits received when handling the stressful and traumatic effects of operational work.

Research purpose: The objective of this study was to describe the concepts of multifaceted social support network systems as perceived by SAPS members in the context of the Vhembe District (South Africa) in assisting them to deal with the effects of their operational work.

Motivation for the study: There is still a call in social research to focus on the influence of different functions and sources of social support.

Research design, approach and method: A descriptive phenomenological research design was used, and 20 SAPS participants were selected through purposive sampling. Unstructured, face-to-face interviews, field notes, telephone follow-ups and diaries were used to collect data which was subsequently analysed through phenomenological explication.

Main findings: The results show that social support is not a linear process but is multifaceted, depending on specific operational settings. Furthermore, the social support network system identified is informed by the values of communal living in the Vhembe District as well as in the operational context in which the SAPS members work.

Practical/managerial implications: The SAPS should help initiate and involve, during the debriefing of operational members, types and functions of social support that are dependent on organisational and community contexts.

Contribution/value-add: This study makes a meaningful contribution to understanding that social support in the SAPS operational context is different from other contexts.

\section{Introduction}

\section{Problem statement}

The purpose of this study was to describe the concepts of multifaceted social support network systems as perceived by the South African Police Service (SAPS) members in the context of the Vhembe District (South Africa) in assisting them to deal with the effects of their operational work (work that involves managing critical incidents).

The work of SAPS members is characterised by high levels of brutality and stress as well as a high risk for suicide. Whilst the SAPS members have to protect others, the environment in which they serve is not safe for them (Bazana \& Dodd, 2013). They form part of a group of first responders who serve the immediate needs of community members when traumatic incidents occur. Exposure to such incidents leaves them in physical and mental states of health that require social support from others (Prati \& Pietrantoni, 2010).

According to Patterson (2003), levels of social support after exposure to traumatic experiences account for differences in reactions to such experiences. It is shown that trauma victims with social support tend to cope better compared to those without social support. This support is also seen as a buffer against psychological stress, which is a result of life and work-related events. The reason is that social support serves as a problem-focused coping strategy which is geared towards gathering information in order to face the problem encountered. It is also an emotion-focused coping strategy that regulates the emotions experienced (Marivate \& Madu, 2007; Patterson, 2003).

Whilst there is a relationship between social support and mental health amongst first responders on the assumption that social support mediates stress, one also finds mixed evidence of a strong and insignificant association between the two in critical incidents (Prati \& Pietrantoni, 2010). This mixed evidence pertains to the following: Varying theoretical assumptions have been revealed 
of models that cite social support as a predictor of coping after critical incidents and social support that serves as a precipitating factor of distress, especially due to talking about the horror experienced under very stressful situations. Types of social support, received and perceived, are also reported to be unequally related to mental health (Prati \& Pietrantoni, 2010). The implication here is that social support is significant in predicting mental health, but the contexts in which it is used, the factors that increase its effect, its mediators, the psychosocial and physiological mechanisms by which social support ensures coping, the influence of the functions of social support, the different sources of social support and the impact of stress are still not clear as they all play different roles in the effect of social support (Prati \& Pietrantoni, 2010).

It has also been found that, when a particular person is implicated in a problematic situation, support for that person may not mediate the effects of distress. On the contrary, the person who is not the cause of the problem is most likely to offer effective support (Patterson, 2003). This further shows the necessity to look at the influence of the implicated or non-implicated source during social support. Kasayira, Chipandambira, Hungwe and Mupawose (2007) indicate that the effectiveness of coping strategies is also dependent on the victims' subjective interpretations of the stressors to which they were exposed and the meanings they attached to these. They show that past experience and efficacy in the use of strategies also play a mediating role. Therefore, coping is a subjective matter that has different connotative meanings to different individuals. This also has implications regarding the effectiveness of relying on social support as a coping strategy.

Current studies on social support recommend that future research should move beyond confirming the effectiveness of social support in ensuring well-being. It should focus on the influence of different sources of social support and how they function to improve mental health (Prati \& Pietrantoni, 2010; Thoits, 2011). Kawachi and Berkman (2001) show the main reason for this to be the fact that social support has different effects amongst different groups in society. Such studies have not yet been conducted amongst operational SAPS members (those dealing with traumatic cases) in the Vhembe District. Such a study would aim at identifying sources of social support that are peculiar to operational members, in particular in a rural district such as Vhembe. Based on the inconsistencies in the literature and the recommendations for further research, this study sought to describe the value of different sources of social support from outside the operational SAPS members' workplace in order to identify the mechanisms of social support and the benefits of the support. The aim was to reveal social support concepts in the identified context.

\section{Literature review}

\section{The concept of social support}

Social support is a multidimensional construct that provides emotional, informational, appraisal and tangible resources for coping (Berkman, Glass, Brissette \& Seeman, 2000; Kaniasty \& Norris, 2000) by offering assistance within an interpersonal relationship that comprises reciprocal exchange of resources between those involved (Finfgeld-Connett, 2005; Hobfoll, Jackson, Hobfoll, Pierce \& Young, 2002). Social support mainly takes the form of talking to someone about the problem encountered and gathering information on possible solutions and other resources in order to cope with the problem (Marivate \& Madu, 2007; Patterson, 2003). Finfgeld-Connett (2005) emphasises that this concept is specific to particular contexts and may change with changing circumstances. It is negotiated and works best when occurring in a caring and non-judgemental environment.

Social support is different from the concepts of self-mastery (belief in one's ability to handle stressful situations), communal mastery (belief of overcoming stressful situations by being part of a group that values one and shares efficacy in handling the situations without necessarily going to others for support) (Hobfoll et al., 2002) and communal social support (high mobilisation of support after the occurrence of a catastrophic situation, which is more complex than social support) (Ben-Zur, 2008).

The social networks and type of social support received determine the effectiveness of coping (Marivate \& Madu, 2007; Patterson, 2003). Such networks generally include people who have gone through the same experience or anyone who has not necessarily encountered the problem at hand but with whom one feels free to discuss one's problem. It also has the potential to offer assistance and encouragement as well as sharing common spiritual values (Gumani, 2012). Finfgeld-Connett (2005) adds factors such as common demographic and sociocultural aspects. Therefore, examples of sources of support are spouses, other family members, colleagues, supervisors, friends, peers, neighbours, church members, support groups, health care professionals, teachers and acquaintances (Ciarrochi \& Deane, 2001; Finfgeld-Connett, 2005; Patterson, 2003).

Finfgeld-Connett (2005) and Ciarrochi and Deane (2001) draw a distinction between professional and nonprofessional social support. Specific types of nonprofessional social support noted are the following: (1) Emotional support is geared towards alleviating emotional responses to problematic situations such as anxiety, uncertainty, hopelessness and depression. This is achieved through the physical availability of the supporting figure or emotional support such as attentive listening, prayer, sending gifts or the use of social media to communicate as well as the use of comforting gestures and redirecting thoughts and feelings about the situation; (2) instrumental support is focused on providing concrete items and services such as transportation, physical care and task assistance (Finfgeld-Connett, 2005).

The outcomes of social support vary according to contexts. For instance, amongst some, the expression of one's thoughts and emotions helps whilst, amongst others, this may lead to aggravating the situation. Generally, social support aims to empower one to have control over the problem through strategies like reassurance, reinforcement, affirmation, validation and encouragement. The consistent availability 
and quality of support provided in the social networks are important. All of these ensure improved mental health, perceptions of well-being and the personal ability to handle situations (Finfgeld-Connett, 2005). Social support is generally deemed effective when related to expectations. It can ensure health either directly or indirectly through an individual's cognitive mechanisms. For instance, optimism, the tendency to expect positive outcomes during stressful situations, leads to psychological well-being. This is due to the use of problem-focused coping strategies and effective emotional regulation (Karademas, 2006).

This conceptual definition of social support helps to understand the role of social support when faced with distressing events. The current study may make a further contribution in this area of knowledge, especially focusing on police members who deal with traumatic cases.

\section{Research design}

\section{Research approach and strategy}

When deciding to embark on this study, I was of the opinion that the operational SAPS members in the Vhembe District do rely on social support for survival, but I was curious about how this concept is constructed within their social interactions. As a result, a qualitative, phenomenological research design that focuses on the systematic investigation of the content and the organisation of conscious experience was adopted (Bryman, 2008). Descriptive phenomenology was utilised to describe, as narrated by the participants, core concepts and essences pertaining to the participants' social support. Even though descriptive phenomenology claims that descriptions emanating from such an inquiry are not influenced by history and contextual features such as the social, cultural and political settings in which people live, this cannot be guaranteed in the present study. Nevertheless, participants' common experience and what they consciously know about the social support received was described (Lopez \& Willis, 2004).

The description comprised categories of the perceived nonprofessional social support networks that benefit the SAPS members when doing operational work. Bracketing (restraining my preconceptions and reflecting on personal and expert knowledge about this experience) was essential. I did this by writing them in a journal to prevent them from impacting on the inquiry that I was conducting. A brief literature review on the conceptual definition of social support helped with meaningful phrasing of the research question. An extensive literature review was conducted after the data analysis to contextualise the findings. This added to rigour by ensuring credibility in conducting a phenomenological inquiry in this study (Lopez \& Willis, 2004).

\section{Research method}

\section{Research setting}

The study was conducted in the Vhembe District in the Limpopo Province of South Africa. The district is situated in the northernmost part of the province. The Thulamela and
Mutale municipalities comprise the areas in which the study population was identified and from which the sample was drawn. The district is fundamentally rural with the majority of people speaking Tshivenda. It has more female than male residents (Grobler, Van Vuuren \& Zaaiman, 2011). There is easy access to police stations in major areas and villages in which visible policing is apparent.

\section{Entry and establishing researcher role}

The ethics committee at the Department of Psychology at the University of South Africa provided me with ethical clearance to conduct the study. The Provincial Commissioner of Police in Limpopo also granted me permission. Permission was then given to station commissioners in the identified police stations and units, who provided lists of police members who could participate in the study. I identified to all who provided authorisation and to the participants my role as a doctoral student working on a thesis.

\section{Selection of participants}

To select participants, I used purposive sampling, which focuses on finding participants who know about and have experience regarding the phenomenon under study (Franchuk, 2004). The participants were 20 police members in units working with family violence, child abuse and sexual offences (FCS), domestic violence, field training, detective and social-crime prevention. They usually work on cases such as murder, rape, domestic violence and road accidents which involve victims of trauma. The sample number was determined by reaching data saturation (Strauss \& Corbin, 1998). The focus was on the Thohoyandou, Siloam, Vuwani, Levubu, Mutale, Tshaulu and Makuya policing areas in the Vhembe District. The participants had knowledge of the topic under study and managed to share as much information as possible on their experiences of social support when faced with traumatic cases. This facilitated the collection of data that was relevant to the aim of the study (Cutcliffe, 2005).

The characteristics of the sample were as follows:

- 19 Tshivenda-speaking and one Xitsonga-speaking SAPS members

- male and female participants

- participants in the constable, sergeant, inspector, captain and superintendent ranks

- participants with seven months to 24 years of experience working in a unit

- both single and married participants

- participants affiliated to the Christian religion

- levels of education that varied from Grade 10 to a university degree

- an age range of $27-55$ years.

\section{Data-collection methods}

I conducted individual, face-to-face, unstructured interviews (Strauss \& Corbin, 1998) which lasted for a minimum of an hour. The following question was asked: 'What is the basic function of social support, received from outside of 
the work environment, in the life of an operational SAPS member?' This question resulted in a conversation between the participant and I, which led to gathering detailed data on the types and functions of social support received. The question was supplemented with follow-up questions in order to gather more data and to describe common concepts pertaining to the participants' experience of receiving social support from outside of the work context. Weekly entries on the functions of social support into diaries also added to the data (Franchuk, 2004).

\section{Recording of data}

Interviews were recorded, using a digital voice recorder to record the responses of the participants and ensure repeated re-visitation of the data during data analysis. Field notes were also taken during the initial interviews to record vital information and to help with follow-up questions.

\section{Data analysis}

A phenomenological explication method adopted from Hycner (1985) was used to analyse data manually as follows:

- verbatim transcription of data into text

- noting the nonverbal and para-linguistic communication of general meaning

- open reflection on the emerging meanings

- repeated listening to and reading every word, sentence, phrase and paragraph for a sense of the whole

- applying the research question to the identified units of meaning, which helped to clarify the research question thus noting the unit of relevant meaning.

Redundant units of relevant meaning were eliminated by looking for literal content, the number of times and how a unit of relevant meaning was mentioned. The chronology of events was also noted. Any units of relevant meaning that could be clustered together were determined through further reflection, and central themes were extracted to express the essence communicated by those clusters. A summary was made of each participant's information. The steps conducted above were repeated in order to modify the summary. General and unique themes were placed within the context in which they emerged by looking for and quoting raw data from the texts that supported those themes. A composite summary of all the texts which accurately captured the essence of the phenomenon under study was written. Findings were presented in the form of conceptual themes.

\section{Strategies to ensure quality data}

The research question and methodology for conducting the study were set out before the study commenced. A pilot study was also conducted. This ensured that the interview questions were relevant.

\section{Ethical considerations}

Participants were informed of the purposes and procedures of the study. Individual letters of consent were signed by the participants as proof of their willingness to participate in the study. Data that was recorded on a voice recorder was deleted after transcription. This was done to ensure confidentiality. For the purpose of anonymity, participants were referred to by their position at work and gender rather than by name. Potential emotional harm was also prevented by not forcing them to talk about issues that they found too sensitive to disclose (Seale, Gobo, Gubrium \& Silverman, 2004). In addition, debriefing by a clinical psychologist was arranged, but this arrangement was not welcomed. Consequently, pamphlets designed by a clinical psychologist on how to cope with vicarious traumatisation were distributed to the participants.

\section{Trustworthiness}

As a way of ensuring rigour, two promoters of the thesis served as judges to independently verify the extracted themes during data analysis. I also engaged the participants telephonically to present a summary of the themes by entering into dialogue with them before the findings were published (Leedy, 1997). The goal was to ensure accurate representation and comprehensiveness, thus noting the credibility and confirmability of findings. Triangulation through the various data-collection methods (individual, face-to-face unstructured interviews, field notes, follow-ups and diaries) also enhanced the credibility and confirmability as well as the transferability of findings (Yardley \& Marks, 2004). Confirmability was ensured through assessment by the thesis promoters (Bryman, 2008).

\section{Findings The multifaceted, social support network system of operational SAPS members}

This section describes multifaceted social support, which refers to support that is received from outside of the work environment from various groups of people who are significant others in the lives of SAPS members. These are family members, pastors at church, friends, community members and victims' next-of-kin.

\section{Support by family}

Family members are usually the first people from outside of work to whom the members turn for support when faced with critical incidents at work. Two reasons account for people looking at family members for support first. Firstly, there is the nature of the composition of the family. Family support is received from different members depending on the nature of relationships within the family and the degree of closeness. Secondly, family traditions in the Vhembe District determine who the people are to whom one may disclose your problems, based on marital status, gender and matriarchal or patriarchal status. Amongst married male SAPS members, spousal support is the most common form of family support. Unmarried members usually resort to sharing with their parents. Support from mothers and mothers-in-law is common amongst married female members. Male members generally receive support from other males like their elder 
brothers. For instance, a female FCS constable indicated the following:

'Sometimes when I return from work, I share with my mother and mother-in-law about what I experienced. They comfort me and share ideas with me on what to do when I am at work ... The encouragement and motivation that I receive from home when they tell me to go to work helps because there are days on which I do not feel like going to work.'

A male detective inspector responded as follows: 'I also talk to my elder brother.'

Wives' support entails extensive information sharing on operational experiences. This type of sharing tends to be initiated by the members, and it creates an arena in which the members are able to divulge all and detailed information about the cases that they investigate. The reasons for this extensive sharing with their wives include the experience of trauma reactions which necessitates help from a person with whom one is very close. A wife can keep the information confidential as it is shared with her in strict confidence, and wives are regarded as the most reliable sources of information that can assist with investigations if the members die in the line of duty. The wives will be able to provide information on what the members used to talk about when they came back from work and to identify the cause(s) of their death. Having the experience of many years of marriage also makes it easier for members to trust their wives with the information. Some members describe their wives as 'supportive wives' or 'friends'. Others also refer to them as 'second-in-charge' and 'deputies'. An example is a response by a male detective inspector:

\footnotetext{
'She must know what I went through during the course of the day ... If I do not get a response from talking to myself then I will get a response from the second in-charge. If I need a deputy then the deputy is my wife.' A constable in social-crime prevention also indicated: 'I talk to my wife about everything. We have been married for 21 years now, and she has never divulged the information that I told her in the strictest confidence. She is my best friend. I tell her everything.'
}

In other instances, selective information sharing takes place as the members are governed by the confidentiality principle that is enforced at work regarding the disclosure of workrelated information. In this instance, support could be sought when the members' wives notice unhappiness in the members when they return from work, and this is possible in a relationship wherein the communication of emotions is valued. Members' wives can also deduce case information from the phone calls that members receive at home. The older the wife is the less information is divulged to her in order to protect her mental health.

Mothers may no longer be seen as part of the married male members' immediate families. According to them, a mother becomes part of a man's extended family as soon as the man gets married. Therefore, members may share general operational experiences with mothers compared to the wives with whom they share specific information. One of the male detective inspector's response accounts for this:

'My mother is no longer a part of me. She is a part of her own family. Therefore, there are different ways of talking about these issues. When I talk to my mother I only talk about what I am faced with at work and how difficult it is.'

Familial support is generally received when there is a preoccupation with traumatic cases and a lack of debriefing services at the workplace after exposure to the traumatic cases. In other words, it takes place when the investigation of a case is perceived as difficult. Experiencing traumatic situations on a Friday, a day that marks a break from operational work, also determines the use of this strategy. Such experiences cause the members to seek help from the social support network systems outside of the work environment.

Benefits of spousal support include lessening trauma reactions, preventing the members from attending to cases when off-duty, detection of emotional withdrawal, helping the members to feel comforted and improved communication between the members and their wives. The general benefits of familial support include being encouraged to tolerate the operational work, re-directing negative perspectives of cases, being reassured that they can do the work and preventing mental exhaustion.

\section{Support by pastors}

This is a spiritual form of support which entails taking the initiative to receive support from a pastor in one's home church in order to share experiences from work. It could be a strategy used on Sundays when the members go to church, thus seizing the opportunity of formally gathering with their fellow church members. It could also entail an everyday action that involves a regular invitation of pastors to their own homes. For instance, a male detective inspector indicated that '[o]ur pastors visit us in our homes. They usually come to offer us prayers.'

Sharing experiences is also inclined to be selective in this case to avoid disclosing confidential information about cases. Such sharing includes disclosing stressful situations which are often described as 'nerve-wracking' or 'painful' and members' changed views about the safety of humankind. A male FCS inspector said:

'I talk to my pastor when I have come across nerve-wracking situations and experience stress ... When I feel that I cannot accept the situation then I ask him that we pray about the situation. I ask my pastor that we pray about certain situations as we can see that Satan is trying to destroy people.'

The pastors are regarded by some members as figures with whom they are closest outside of the work environment. A male detective inspector said: 'The people who are able to encourage us are pastors because they are the ones that we are very close to out there.' A compelling factor for resorting to this form of support is handling traumatic cases such as murder and rape during the first year of work. In such cases, members need much encouragement to continue with operational work. This helps with perceiving operational work positively and being encouraged to continue with work. This strategy thus plays a mediatory role. 


\section{Support by friends}

Experiencing traumatic cases on a Friday, especially preoccupation with thoughts about the scenes to which they were exposed, necessitates turning to the support of friends. This form of support also entails the selective sharing of experience. Even though all the people in this form of support network are friends, the borders of the friendships vary, and such variations determine the types of issues shared and the degree of sharing. Two types of friendships are shown: close friendships and less intimate friendships. The members tend to share more operational experiences with those who are the closest to them. Nevertheless, across the different friendships, information sharing is implicit in nature as traumatic operational experiences are not communicated clearly but are implied by the statements uttered. The friends' support involves giving advice on how to handle cases. This is shown by the response of a male inspector in social-crime prevention: 'They give advice on how to handle the cases.'

\section{Support by the community}

Community support also forms part of the multifaceted support network system. This support takes place in the form of collaboration with community structures, mainly through organisations like community policing forums. Community leaders, including chiefs, and civic associations, which are local leadership groups usually found in rural settings, form part of this collaboration between the police and community members. The members also receive support through community members who use the organisation Youth against Crime to report on crime. Partnerships are formed between these organisations and the members as arranged by the SAPS. A male constable in social-crime prevention accounts for this:

'We receive support from the community members when they form a partnership and collaborate with the police. I mean that there are organisations such as CPF and the Youth Against Crime.'

Experiencing traumatic experiences on Fridays further incites the use of this form of support. When using this strategy, the members receive what they regard as 'improved support' from the communities that they serve. This is because community members no longer hide information pertaining to the cases that the SAPS members investigate as they used to before. These forms of community support help to develop the mutual sharing of traumatic experiences between the police and the community. For instance, a female FCS inspector said:

'We also go to community meetings as we are sometimes invited to chiefs' kraals whereby community members bring their problems. As we discuss these problems with them we feel that we are also sharing our own problems with them.'

Some SAPS members attribute this to working in a district (Vhembe District) in which policing areas have predominantly one tribe, compared to other areas which comprise several tribes in one area. According to them, the latter compromises the cultural values established and adopted in an area.
Communal living and having elders within families assist in the resolution of problems, particularly in cases like domestic violence. This is regarded as a factor that encourages discussions about the traumatic cases within families and between community members and the SAPS members. A female constable in social-crime prevention pointed out the following:

'Situations that we come across here are less severe compared to those in Gauteng. They are different because there is mostly one tribe living here ... If there is a domestic problem here, people are still able to involve uncles and aunts as they still live as extended families. They help us with reducing some pressure.'

Whilst addressing community members on the traumatic crimes is part of the SAPS members' work, this form of sharing creates an arena of 'informal therapy' for the SAPS members because listening to the community members' traumatic experiences and the SAPS members sharing their own experiences leads to an exchange of traumatic experiences. Such sharing is regarded by the SAPS members as an opportunity of 'sharing own problems'. It means that listening to 'other' traumatic experiences may not necessarily predispose an SAPS member to vicarious traumatisation (VT; being affected as a secondary victim by a critical incident) but can actually help. Sharing does not only provide an opportunity for the representation of the views and experiences of the community members regarding traumatic cases, but it provides a representation of the views and experiences of the SAPS members as well.

In the case of these SAPS members, support by the community as a form of help appears to be dependent on the following conditions: Firstly, one finds the type of victims with whom they share, in this case, exposure to victims who are not involved in traumatic situations at that particular time but were in the immediate past. Secondly, one finds exposure to the stories of fellow secondary victims as some of the community members are also secondary victims of those crimes just like the SAPS members are. The reasons for this is that those community members are not directly involved in the traumatic situations that they share, but they are either observers of traumatic scenes or they heard about the traumatic crimes that have been committed in their neighbourhoods. Sharing with such people provides the members with motivation to survive, and it emanates from the sharing of similar traumatic experiences. The strategy of receiving support from community members is thus both community oriented and self-oriented. Lastly, the atmosphere of exposure, which in this case is the experience of mutual sharing in a group rather than a unilateral exposure to others' traumatic experiences, also mediates the occurrence of VT. Therefore, these three factors, serve as factors that moderate VT amongst SAPS members. This process of sharing also compensates for the unavailability of debriefing services. In the end, the SAPS members are able to deliver the results that are expected at work such as proving cases and arresting the perpetrators. This makes their operational work easier to execute. 


\section{Support by the next-of-kin of victims}

Worth noting is the support that SAPS members receive from the victims' next-of-kin, particularly in cases such as murder. Whilst this form of support is not expected, some of the relatives of the murdered victims show understanding of the members' situations, mainly when they realise that the members are as much distressed by those victims' traumatic situations as they as relatives are. They also encourage the members to continue with case investigations, inquire about progress made and show appreciation for the effort that the members make in solving their cases even if the members fail to arrest the perpetrators. They do not expect that the members should render them a service by detecting evidence in cases without being empathic towards these members. Whilst these members offer police support to the victims' relatives, the victims' relatives provide them with social support. The response by a male detective inspector shows this: 'They may provide a lot of support. Even when they phone, they speak to me in such a way that they show understanding of the effort that I made.'

This form of support adds to the assistance that is received from other supporting parties. Like the other forms of support, support from the next-of-kin of victims is also mentioned in relation to the absence of debriefing services at work. The understanding that the victims' relatives show regarding the experiences of the SAPS members strengthens the members enough to face the work.

\section{Indiscriminate support}

A small portion of the SAPS members indicate that there are no specific preferred persons outside of the work environment with whom to share operational experiences. They would share with anyone, thus pointing to indiscriminate support within and outside of the family. The unspecified people outside of work, nevertheless, have to meet the following criteria for them to be considered as suitable persons with whom to share operational work experiences. Firstly, they should have close relationships with the members. As such, family members, friends and acquaintances are included in this social support network system. Secondly, they should have the ability to put the members' operational experiences into perspective in order to help them cope with those experiences. Thirdly, this relationship should include the possibility of mutual problem-sharing with those involved. Therefore, even though they have different experiences as the supporting parties are not police members, it is important for the supporting parties to be able to divulge their own challenges to the members, thus excluding a one-sided form of sharing. Lastly, the supporting parties are also expected to have the ability to calm the members down. A lack of this ability means that they cannot offer the members the expected assistance. The response by a female field training sergeant illustrates this:

'I usually talk to a person that I am close to. It could be a person that I live with at home or a friend who is able to explain to me what is happening to a point that I can gain understanding ... The person that I would be talking to would also tell me about their own experiences. When you hear those words you are able to calm down.'

The reasons for seeking this form of support differ. It is based on the dynamics of the job such as when the SAPS members are supposed to assist elderly victims who disapprove of being helped by the members due to the members' age and their knowledge of the members' poor financial background. The victims thus undermine advice that is given by the members, especially during victim counselling. For instance, a female field training sergeant said:

'Sometimes you come across those things like helping a person
who tells you that she cannot be assisted by you as you are
young or tell you that she knows your background of poverty.
The person will tell you that you cannot tell her anything. This
becomes better when you find someone at home with whom
you can talk to about these things because he/she will calm you
down.'

Seeking this form of support helps the members put their experiences into perspective and to understand the victims, thus serving an educational purpose. In addition, a mediatory role is realised as the members feel calmer, and normal interaction between the members and family members is sustained.

\section{Discussion}

\section{Outline of the results}

\section{The role of context in receiving multifaceted social support}

It appears that SAPS members continue the tradition of a communal way of living that involves the support of various people in their lives in order to deal with traumatic incidents. The support is inspired by the communal living arrangement in the Vhembe District. The support entails collective, versatile and practical support due to resourcefulness in seeking and accepting support of familial, social, spiritual and communal nature. Therefore, the term social support does not fully describe the kind of support that takes place in this context. Hence, I use the term multifaceted, social support network system in this study. Whilst support can be based on emotional, informational, appraisal and tangible resources, with victims of natural disasters relying more on tangible help (Kaniasty \& Norris, 2000), the reliance on multifaceted support amongst the operational SAPS members in this study is based on the exchange of information, situational appraisal and emotional encouragement.

This support is further determined by the operational context in which it takes place, based on the nature of critical incidents encountered and the experience of trauma reactions either during the first year of work or even after years of working as a police member. These are coupled with the time of occurrence of the incidents, specifically Fridays, the dynamics of the member-victim relationships of SAPS members and the non-availability of work-based support in the form of debriefing. The availability of sources of 
nonprofessional support, the nature of social relationships, the family and community values in the Vhembe District and work procedures determine the reliance on social support. Kaniasty and Norris (2000) and Finfgeld-Connett (2005) support this fact by affirming that the nature of social support varies according to unique ecological contexts, especially considering ethnic differences as well as psychological, social, economic and political needs. DeLongis and Holtzman (2005) add that the characteristics of stressors in such contexts also play a role as coping efforts are adjusted according to the stressors experienced. The effectiveness of the chosen coping strategy also differs in various situations.

\section{Sources of support}

This study shows that, whilst most of the sources of social support namely family members, pastors, friends, community members and unspecified people outside of work are similar to the sources of social support for people in the general population (Ciarrochi \& Deane, 2001; FinfgeldConnett, 2005; Kaniasty \& Norris, 2000), the dimensions and properties of these sources tend to be different amongst the subpopulation of operational members. Furthermore, some sources are peculiar to the operational context. For example, SAPS members rely on the next-of-kin of victims and on support from community structures. The latter is also a result of the formal arrangement made on the basis of the SAPS' objective of fostering community policing in curbing crime.

\section{Ranking social support sources and the psychosocial mechanisms of support}

Primary, secondary and tertiary sources were found in this study on the basis of mechanisms of support that these sources offer. In the present study, a primary source's support is successful due to, firstly, intimate closeness. This supports one of Thoits' (2011) definitional aspects of primary groups of support. In the current study, primary groups are people to whom the SAPS members, specifically male members, turn without reservation and with whom the members share intimate relationships, namely the spouses. Secondly, amongst these primary sources, support is enhanced by the ability of the supporters to keep the secrets shared with them. DeLongis and Holtzman (2005) add that marital relationships are the primary support relationships for many adults. They further show the importance of family as the setting in which the closest relationships are found, and they show that the ability of people to thrive despite facing stressful situations may not be understood if this setting is not studied. Lastly, support from primary sources is effective because of marital status indifference (other family members tend to be considered when an SAPS member is not married, which supports Thoits' (2011) idea of people receiving guidance from similar others) and same gender association (unmarried officers tend to seek support from family members of the same gender). Kawachi and Berkman (2001) also cite stage in life and gender as some of the reasons that make social support beneficial in some groups of society.
The effectiveness of secondary sources is determined by the roles played by those sources. According to Thoits (2011), what makes the support from secondary sources effective is the others' approval of one's role of support. The current study also shows that the effectiveness of secondary sources is determined by the sources' successful role in helping the SAPS members cope with critical incidents. DeLongis and Holtzman (2005) also show that some people are preferred as support because of a sense of what is considered to be appropriate coping in a particular situation. Therefore, pastors, victims' next-of-kin and community structures are deemed supportive in cases that relate to these sources' roles in the community. Cases that are regarded to be beyond human comprehension are discussed with pastors because they offer spiritual reinforcement. Victims' next-of-kin mainly provide support when they notice the members' distress due to external factors when investigating cases. Members turn to community structures as well as the organised support recognised in the workplace when there is a need to share case experiences with people who are vicariously affected by the same experiences as the members and who thus understand the distress that the members face. The characteristics of this secondary ranking is also similar to Thoits' (2011) definition of a secondary group of support on the basis of larger, formal interactions that are guided by rules and regulations.

Whilst the above may be regarded as secondary sources compared to spouses and other family members, they may be primary sources in their own right in some settings of operational work, thus showing that social support in this context is not a linear process. Berkman et al. (2000) confirm that social support works through many pathways. In this study, it does not only imply the use of different mechanisms but also of cross-cutting pathways of support. This is one of the contributions that the current study makes as there is increasing interest in research to uncover the large array of mechanisms through which social support improves mental health (Thoits, 2011). Mutual support is another mechanism that makes effective the support by secondary sources, namely the victims' next-of-kin and community structures.

Friends are more inclined to be treated as the last resort because they are mainly needed for information on caserelated solutions. Much information is hidden from them, but cues are given during communication without the disclosure of mental and emotional experiences to merely receive suggestions on methods that can be used to handle cases. This suggests the avoidance of appearing vulnerable before friends. DeLongis and Holtzman (2005) also cite that direct information provision is a strong mechanism for handling some situations effectively. Thoits (2011) confirms that this leads to a sense of mastery over tasks that should be accomplished. This makes friends tertiary sources of support because of the position in which they are put.

The above further shows that the order of ranking of social support, with friends relied upon before outsiders as noted by Kaniasty and Norris (2000), is different in this context. 
The general ranking from intimate to extended relationships suggested by Berkman et al. (2000) is supported. A specific ranking from most intimate (marital ties) and then outward to social networks (close relatives and friends) and to 'weak' ties (such as involvement in community and religious organisations) (Kawachi \& Berkman, 2001) is not supported. The reason for this finding is that, in this study, what are regarded as weak ties that lack person-to-person interactions are actually second, strongly recommended ties that offer both group and individualised interactions. Lin, Ye and Ensel's concept of three layers of social networks, the belongingness-bonding-binding continuum cited in Kawachi and Berkman (2001), explains how these strong ties in community and religious organisations, as outer layers of linkages, can afford people an opportunity to establish closer links such as community participation which may lead to closer interactive ties in social networks. A distinction amongst the ranks of social support made here is an aspect which Thoits (2011) indicates is lacking in literature.

\section{Types of support}

Thoits (2011) explains that the reception or perception of social support is one of the ways of ensuring health in social networks. Consequently, the current study unfolded the following three categories of receiving support, which suggest that aid is generated through different routes.

Solicited support: This kind of support is mainly initiated by the SAPS members with sources that are very close, namely spouses, other family members, pastors and close friends. Other people such as acquaintances and anyone else who is capable of offering the members mutual support may also be approached for help. Under this category, spouses are the only ones with whom extensive sharing of operational work experiences takes place. This is because of the nature of a relationship of intimacy, mutual dependence and utter confidence between a member and a spouse. Selective sharing takes place with different groups of people for various reasons. With spouses, selective sharing may, in some instances, take place due to adhering to the confidentiality principle set at work, and it may also prevent them from being exposed to secondary distressing situations, thus protecting their mental health. Other family members are used as alternative forms of support when the members are home on weekends and away from the workbased support such as colleagues on whom they usually rely. Whilst the latter reason also applies to friends, adhering to the confidentiality principle is strictly paired with this reason amongst friends. Pastors are another group of persons who are slightly subjected to the confidentiality principle. The indiscriminate support of acquaintances and anyone who is capable of mutual support are sought selectively due to only having the desire to share screened information on the job dynamics encountered.

Granted support: Selective sharing with spouses may also be a result of granted support. This is support that is initiated and offered by the sources of support on the basis of compassion towards the members. It appears that spouses, due to the nature of the relationship that they share with members, are some of those within the social support network system who are able to detect the need for support amongst the members and to actually offer such support. DeLongis and Holtzman (2005) report that family members have a tendency of asking the question 'How was your day?' when loved ones return home, which naturally creates an arena for coping responses to be explored. The confidentiality principle and the protection of the spouse's mental health plays a role in sharing during granted support, just as in solicited selective sharing. Victims' next-of-kin are the second group of persons who can grant this form of support. Contrary to the selective sharing with spouses, extensive sharing takes place because the victims' next-ofkin are directly involved and already have information on the cases dealt with by the members.

Collaborative support: Ben-Zur (2008) found no relationship between communal beliefs on support and protection from postraumatic stress in a sample of uprooted Israelis. In contrast, the current study shows that collaborative support, that is, mutual support between two groups which share the same secondary traumatic experiences, reduces trauma reactions. This sentiment is shared by both SAPS and community members. Community members include victims' next-of-kin and other indiscriminate persons, as well as community structures like the community leaders, civic associations, community policing forums and Youth against Crime. Hobfoll et al. (2002) indicate that communal mastery, which can lessen distress, works mainly on the basis of being part of a group without necessarily engaging in physical contact. In this case, five aspects seem to enhance collaborative support and coping. These are communal living, a sense of belonging, physical contact, collaboration and receiving mutual help. These characteristics tend to make sharing to be extensive and appear to combine both aspects of social support and communal mastery. As Hobfoll et al. (2002) suggest, social support and communal mastery can be related. Some of these characteristics of collaborative support are apparent in rural and collectivist communities and reflect successful coping according to the culture to which a member is part. On the basis of the above, it can be concluded that collaborative support is more of an attribute of communal social support. According to the social-network theory, network ties determine the existence of a community, and such a community is determined by specific characteristics (Berkman et al., 2000). The five characteristics described here determine the type of community dealt with in this context, a communal social-supportive community.

This is the reason why Berkman et al. (2000) support the view of studying social networks within the larger social and cultural contexts which determine the structure of those networks and multiple pathways in which these networks lead to health outcomes. Their approach upgrades the focus from merely looking at the influence of psychosocial mechanisms at the micro level and social networks at the mezzo level to social-structural conditions such as culture 
and community-structural relations at the macro level. As Kawachi and Berkman (2001) put it, social support is located within the larger context of macro-social exchanges.

\section{Outcomes}

The different types of support yield the desired results, albeit different. The main benefits are as follows: Spouses help with handling trauma reaction as well as with strengthening family and marital bonds. The support from other family members leads to reassurance that the SAPS members can survive the experience, and it prevents mental exhaustion. Pastors' spiritual intervention helps with re-directing negative thoughts. They and the victims' next-of-kin encourage the members that they can do the work. Friends mainly offer effective proposals on the modus operandi of handling the cases. The community structures assist with the endurance of the members and with case resolution through providing relevant information. Indiscriminate support, like pastoral support, is reported to help with changing the members' negative perceptions and calming down their emotions.

Therefore, four issues are raised here: (1) Three resources of support are apparent, namely informational, appraisal and emotional resources; (2) Informational and appraisal resources are inseparable as appraisal works on the basis of information at one's disposal (Thoits, 2011), and this is the most relied upon support; (3) Multifaceted social support amongst operational members plays restorative, preventive, re-directive, strengthening and empowering roles; (4) VT is mediated amongst these members through the multifaceted social support network system in the Vhembe District.

Table 1 provides a summary of the concepts of a multifaceted social support network system on which the SAPS members in this study relied.

TABLE 1: Concepts of a multifaceted social support network system.

\begin{tabular}{|c|c|}
\hline Category & Subcategories \\
\hline Context & $\begin{array}{l}\text { Operational work (traumatic cases and work procedures) } \\
\text { Non-availability of work-based support } \\
\text { Availability of nonprofessional support in social } \\
\text { relationships } \\
\text { Family and community traditions or values }\end{array}$ \\
\hline $\begin{array}{l}\text { Sources of social } \\
\text { support }\end{array}$ & $\begin{array}{l}\text { Primary sources: Spouses and other family members } \\
\text { Secondary sources: Pastors, victims' next-of-kin and } \\
\text { community structures (community leaders; civic } \\
\text { associations; community policing forums; Youth against } \\
\text { Crime) } \\
\text { Tertiary sources: Friends }\end{array}$ \\
\hline $\begin{array}{l}\text { Psychosocial } \\
\text { mechanisms of } \\
\text { social support }\end{array}$ & $\begin{array}{l}\text { Intimate closeness } \\
\text { Marital indifference } \\
\text { Same-gender association } \\
\text { Supportive source-community role } \\
\text { Critical incident modus operandi }\end{array}$ \\
\hline $\begin{array}{l}\text { Resources of } \\
\text { social support }\end{array}$ & $\begin{array}{l}\text { Exchange of information } \\
\text { Situational appraisal } \\
\text { Emotional encouragement }\end{array}$ \\
\hline $\begin{array}{l}\text { Types of social } \\
\text { support }\end{array}$ & $\begin{array}{l}\text { Solicited support } \\
\text { Granted support } \\
\text { Collaborative support }\end{array}$ \\
\hline Outcomes & $\begin{array}{l}\text { Restorative roles: Trauma-reaction management; } \\
\text { endurance; emotional tranquillity } \\
\text { Preventative roles: Prevention of mental exhaustion } \\
\text { Re-directive roles: Redirecting negative thoughts and } \\
\text { perceptions } \\
\text { Strengthening roles: Strengthening family and marital } \\
\text { bonds } \\
\text { Empowering roles: Reassurance of experience survival } \\
\text { and ability to do the work; proposals on case handling } \\
\text { modus operandi; case resolution }\end{array}$ \\
\hline
\end{tabular}

\section{Practical implications}

The findings are relevant for practice because, when compared to theories of social support, specifically in the workplace, it is shown that the form of social support needed for different employees depends on both the organisational and community contexts. The study's findings also add to the body of knowledge on the types and functions of social support needed by police members who are involved in operational work. The SAPS should help initiate and involve such support during the debriefing of the members after exposure to traumatic cases.

\section{Limitations of the study}

The main limitations are the inclusion of only one participant from the field training police unit, only one Xitsonga-speaker and only Christian participants. More married femalemembers than single members should have also been included to gather data on the extent of support received from husbands. This affected the representation of views from the identified unit, cultural group, other religions and gender respectively. Ascertaining credibility and confirmability through telephone interviews could have been better counteracted with face-toface contact with participants for sincere answers.

\section{Conclusion}

This study makes a meaningful contribution to understanding that social support in the operational context of SAPS differs from other contexts. Social support is also not a linear process but is multifaceted, depending on specific operational settings. The research further shows that, although the phenomenon of social coping has been researched for many years now, the phenomenon is broad and contextually based. It is thus recommended that social support should be embraced in the operational context. Furthermore, research using qualitative and quantitative inquiries should strengthen studies on the qualities of communal living and support in rural-based communities. Such inquiries could uncover and confirm types and the extent of the effectiveness of the mechanisms of support shaped by these qualities in alleviating traumatic reactions amongst operational SAPS members who work in such communities. The influence of the micro, mezzo and macro levels of social networks on psychological health in the operational context of SAPS highlighted in this study can be studied in depth to understand the roles of these networks.

\section{Acknowledgements}

This article was extracted from a doctoral thesis at the University of South Africa, supported by a grant from the University of Venda Research and Publications Committee, with the title: 'A grounded theory of police critical incidents impact management amongst SAPS officers in the Vhembe District, Limpopo Province'.

\section{Competing interests}

The author declares that she has no financial or personal relationship(s) that may have inappropriately influenced her in writing this article. 


\section{References}

Bazana, S., \& Dodd, N. (2013). Conscientiousness, work family conflict and stress amongst police officers in Alice, South Africa. Journal of Psychology, 4(1), 1-8.

Ben-Zur, H. (2008). Personal resources of mastery: Optimism, and communal support beliefs, as predictors of posttraumatic stress in uprooted Israelis. Anxiety, Stress and Coping, 21(3), 295-307. http://dx.doi.org/10.1080/10615800801956177

Berkman, L.S., Glass, T., Brissette, I., \& Seeman, T.E. (2000). From social integration to health: Durkheim in the new millennium. Social Science and Medicine, 51 843-857. http://dx.doi.org/10.1016/S0277-9536(00)00065-4

Bryman, A. (2008). Social research methods. New York: Oxford University Press. http://dx.doi.org/10.1557/PROC-1123-1123-P03-08

Ciarrochi, J.V., \& Deane F.P. (2001). Emotional competence and willingness to seek help from professional and nonprofessional sources. British Journal of Guidance and Counselling, 29(2), 233-246. http://dx.doi.org/10.1080/03069880020047157

Cutcliffe, J.R. (2005). Qualitative methods in psychiatric and mental health research. In D. Sallah, \& M. Clark (Eds.), Research and development in mental health: Theory, frameworks and models (pp. 57-75). Toronto: Elsevier Limited. http://dx.doi org/10.1111/j.1365-2850.2005.00869.x

DeLongis, A., \& Holtzman, S. (2005). Coping in context: The role of stress, socia support, and personality in coping. Journal of Personality, 73(6), 1633-1656. support, and personality in coping. Journal of Person
$\mathrm{http}: / / \mathrm{dx}$.doi.org/10.1111/j.1467-6494.2005.00361.x

Finfgeld-Connett, D. (2005). Clarification of social support. Journal of Nursing Scholarship, 37(1), 4-9. http://dx.doi.org/10.1111/j.1547-5069.2005.00004.x

Franchuk, J.E. (2004). Phenomenology vs grounded theory: The appropriate approach to use to study the perspectives of instructional librarians on their roles in information literacy education for undergraduates. Paper written for Interdisciplinary Studies 560, Qualitative Methods. Retrieved October 10, 2005, from http://www.slis.ualberta.ca/cap04/judy/paper.htm

Grobler, M., Van Vuuren, J., \& Zaaiman, J. (2011). Evaluating cyber security awareness in South Africa. In Proceedings of the 10th European Conference on Information Warfare and Security: The Institute of Cybernetics at the Tallinn University of Technology, 07-08 July 2011 (pp. 113-121). Tallinn, Estonia: Cooperative Cyber Defence Centre of Excellence.

Gumani, M.A. (2012). The role of spirituality in the cessation of suicide ideation among the church-going youth in a rural community in the Limpopo Province, South Africa. In Advanced Research in Scientific Areas: The 1st Virtual International Conference, 03-07 December 2012 (pp. 822-828). Zilina, Slovakia: Thomson Ltd.

Hobfoll, S.E., Jackson, A., Hobfoll, I., Pierce, C.A., \& Young, S. (2002). The impact of communal-mastery versus self-mastery on emotional outcomes during stressful conditions: A prospective study of Native American women. American Journal of Community Psychology, 30(6), 853-871. http://dx.doi.org/10.1023/A:1020209220214
Hycner, R.H. (1985). Some guidelines for the phenomenological analysis of interview data. Human Studies, 8, 279-303. http://dx doi.org/10.1007/ BF00142995

Kaniasty, K., \& Norris, F.H. (2000). Help-seeking comfort and receiving social support: The role of ethnicity and context of need. American Journal of Community Psychology, 28(4), 545-581. http://dx.doi.org/10.1023/A:1005192616058

Karademas, E.C. (2006). Self-efficacy, social support and well-being: The mediating role of optimism. Personality and Individual Differences, 40, 1281-1290. http:// dx.doi.org/10.1016/j.paid.2005.10.019

Kasayira, J.M., Chipandambira, K.S., Hungwe, C., \& Mupawose, A. (2007). Stressors and coping strategies of state university students in a developing country. Journal of Psychology in Africa, 17(1), 45-50.

Kawachi, I, \& Berkman, L.F. (2001). Social ties and mental health. Journal of Urban Health: Bulletin of the New York Academy of Medicine, 78(3), 458-467. http:// dx.doi.org/10.1093/jurban/78.3.458

Leedy, P.D. (1997). Practical research: Planning and design. Ohio: Merrill, an Imprint of Prentice Hall.

Lopez, K.A., \& Willis, D.G. (2004). Descriptive versus interpretive phenomenology: Their contributions to nursing knowledge. Qualitative Health Research, 14(5) 726-735. http://dx.doi.org/10.1177/1049732304263638

Marivate, P., \& Madu, S.N. (2007). Levels of social support and coping strategies in adult survivors of child sexual abuse. Journal of Psychology in Africa, 17(1), 133-136.

Patterson, G.T. (2003). Examining the effects of coping and social support on work and life stress among police officers. Journal of Criminal Justice, 31, 215-226. http://dx.doi.org/10.1016/S0047-2352(03)00003-5

Prati, G., \& Pietrantoni, L. (2010). The relation of perceived and received social support to mental health among first responders: A meta-analytic review. Journal of Community Psychology, 38(3), 403-417. http://dx.doi.org/10.1002/ jcop.20371

Seale, C., Gobo, G., Gubrium, J.F., \& Silverman, D. (2004). Qualitative research practice London, UK: SAGE Publications. http://dx.doi.org/10.4135/9781848608191.d32

Strauss, A., \& Corbin, J. (1998). Basics of qualitative research: Techniques and procedures for developing grounded theory. New Delhi: Sage Publications.

Thoits, P.A. (2011). Mechanisms linking social ties and support to physical and mental health. Journal of Health and Social Behavior, 52(2), 145-161. http://dx.doi. org/10.1177/0022146510395592

Yardley, L., \& Marks, D.F. (2004). Introduction to research methods in clinical and health psychology. In D.F. Marks, \& L. Yardley (Eds.), Research methods for clinical and health psychology (pp. 1-20). New Delhi, India: Sage Publications. 